\title{
IMPACTS OF TOURISM DEVELOPMENT AND TOURIST ACTIVITIES ON ENVIRONMENT IN SCENIC ECOTOURISM SPOTS
}

\author{
LIU, L. ${ }^{1,2}-$ KONG, L. ${ }^{3,4}-$ FENG, Y. X. $.^{1,2^{*}}-$ QIN, D. D. ${ }^{1}-$ MAO, N. ${ }^{1}$ \\ ${ }^{I}$ School of Art and Design of Zheng Zhou University of Light Industry \\ Zhengzhou 450002, China \\ ${ }^{2}$ Henan cultural industry development research base, Zhengzhou 450002, China \\ ${ }^{3}$ International Education College of Zheng Zhou University of Light Industry \\ Zhengzhou 450002, China \\ ${ }^{4}$ Business School, Edinburgh Napier University, Edinburgh EH14 1DJ, UK \\ *Corresponding author \\ e-mail:2505000065@qq.com \\ (Received $3^{\text {rd }}$ Apr 2019; accepted $17^{\text {th }}$ May 2019)
}

\begin{abstract}
Scenic ecotourism spots, as major attractors of tourists, boast great economic values and development potentials. Many local governments have developed a series of tourism resources with the aim to fully utilize resources and promote regional economy. However, the tourism development has exerted negative environmental impacts on scenic ecotourism spots. Targeting Xixi Wetland Park, Hangzhou, southeastern China's Zhejiang Province, this paper explores the effects of tourism development and tourist activities on the soil and water environments in scenic ecotourism spots, and draws the following conclusions: The environment in the ecotourism scenic spot is influenced in varied degrees by both tourism development and tourist activities; soil porosity can characterize how tourism development and tourist activities affect the environment of scenic ecotourism spots; the impacts of tourism development or tourist activities on scenic ecotourism spots can be demonstrated by the $\mathrm{pH}$, chemical oxygen demand (COD), total ammonia nitrogen (TAN) and turbidity of water bodies.
\end{abstract}

Keywords: ecotourism scenic spots, tourist resources, tourist activities, tourist development, environmental impact

\section{Introduction}

The ecological environment should be fully protected, because it is the common wealth of all humans (Movono et al., 2018). In China, the rapid development of tourism has brought many problems to resource, environment and management. Many local governments have developed a series of tourism resources with the aim to fully utilize resources and promote regional economy. However, the tourism development has exerted negative impacts on ecological environment, especially in scenic spots (Olafsdóttir and Runnstrom, 2009; Anctil and Blanc, 2016). According to incomplete statistics, more than one-fourths of scenic ecotourism spots in China have been damaged by tourism development, causing degradation of tourism resources and weakening of ecological functions (Aryal et al., 2018). Tourism development has a long-lasting impact on ecological environment. In fact, the ecological impact of a development project persists throughout the construction process. The full-lifecycle impact has been observed in many scenic ecotourism spots (Iliev and Dejan, 2018). 
The ecological impacts of tourism development and tourist activities can be divided into environmental impacts and non-polluting ecological impacts (Wu and Tsai, 2016). Focusing on scenic ecotourism spots, the existing studies have mainly explored the ecological impacts of tourism development from soil erosion degree, biodiversity index, vegetation cover change rate, biomass loss, habitat function and water environment quality, revealing that the continuous tourism development and tourist activities have led to changes in ecological function (Ke, 2012; Lyon et al., 2017). In environmental ecology, the environmental impact in scenic ecotourism spots is relative to the ecological impact of tourism pollution, and the environment of scenic ecotourism spots should be dominated by natural landscape, supplemented by artificial tourism construction and development (Ingelmo and Abedin, 2013). Targeting the Xixi Wetland Park in Hangzhou, southeastern China's Zhejiang Province, this paper investigates how tourism development and tourist activities affect the soil and water environment in scenic ecotourism spots, and analyzes the factors affecting the environment of the ecotourism scenic spot.

\section{Methodology}

Tourism development and tourist activities have concentrated impacts on the ecotourism environment. The impacts can accumulate over time but the intensity is on a gradual decline (Mbaiwa, 2011). For a species in the ecological environment, it will actively adapt to the changes in its habitat induced by tourism development or tourist activities; otherwise, the species will be naturally eliminated. If the species can survive and reproduce in the new habitat, the original ecosystem will be changed substantially (Sigurðardóttir and Steinthorsson, 2018).

For tourism development and tourist activities, the impacts on scenic ecotourism spots have three dimensions: intensity, frequency and duration. The ecological species will not be severely damaged if all three dimensions are controlled within a reasonable range (Saarinen and Lenao, 2014). The development of an ecological community is dynamic, rather than instantaneous. The general process includes such four phases as non-interference, co-interference, sharing and evolution. Any organism failing to adapt to co-interference will be eliminated (Dillimono and Dickinson, 2015). The factors in the ecosystem are mutually constrained, and a complete ecosystem must be open and balanced.

To attract more tourists, the Xixi Wetland Park has developed many tourism projects and conducted various tourist activities, which are bound to influence the environment of the scenic spot. The park environment is dominated by water, soil and vegetation. For simplicity, this paper attempts to disclose how tourism development and tourist activities affect the soil environment and water environment, and identify the factors affecting the environment of the ecotourism scenic spot. To test the soil environment, several soil samples were collected from a sample plot and subjected to measurements of $\mathrm{pH}$, water content, porosity and heavy metal content. A total of ten sampling points was arranged, and divided into mixed points and control points. Note that each pair of mixed point and control point were from similar areas. To test the water environment, several water samples were collected from ten sampling points, and subjected to measurements of $\mathrm{pH}$, chemical oxygen demand (COD), total ammonia nitrogen (TAN) and turbidity. The test methods for Soil and water index test methods are listed in Table 1. 
Table 1. Test methods for soil and water indices

\begin{tabular}{c|c|c|c}
\hline Soil testing indicators & Method & Water testing indicators & Method \\
\hline PH & Potential method & PH & Glass electrode method \\
\hline Water content & Drying method & Chemical oxygen demand & Dichromate method \\
\hline Porosity & Paraffin process & Ammonia-nitrogen value & Spectrophotometry \\
\hline Heavy metal content & Spectrophotometry & Turbidity & Spectrophotometry \\
\hline
\end{tabular}

\section{Test Results}

\section{Impacts of tourism development and tourist activities on soil environment}

The soil environment provides the species of scenic ecotourism spots with the venue to exchange materials. The impacts of tourism development and tourist activities on the soil environment is directly reflected by the the variation in the physical state of the soil and the change of the species. The development intensity or activity scale is positively correlated with the soil aggregation and compaction. On the development intensity/activity scale of tourism, the ten sampling points can be ranked as No. $7>$ No. $8>$ No. $2>$ No. $1>$ No. $4>$ No. $6>$ No. $5>$ No. $10>$ No. $9>$ No. 3 .

Figure 1 shows the change of water content of mixed samples and control samples at different sampling points. It can be seen that the two types of samples had the same trend of water content, but the trend was not consistent with the variation in development intensity/activity scale. Thus, the water content variation cannot mirror the environmental impacts of tourism development or tourist activities.

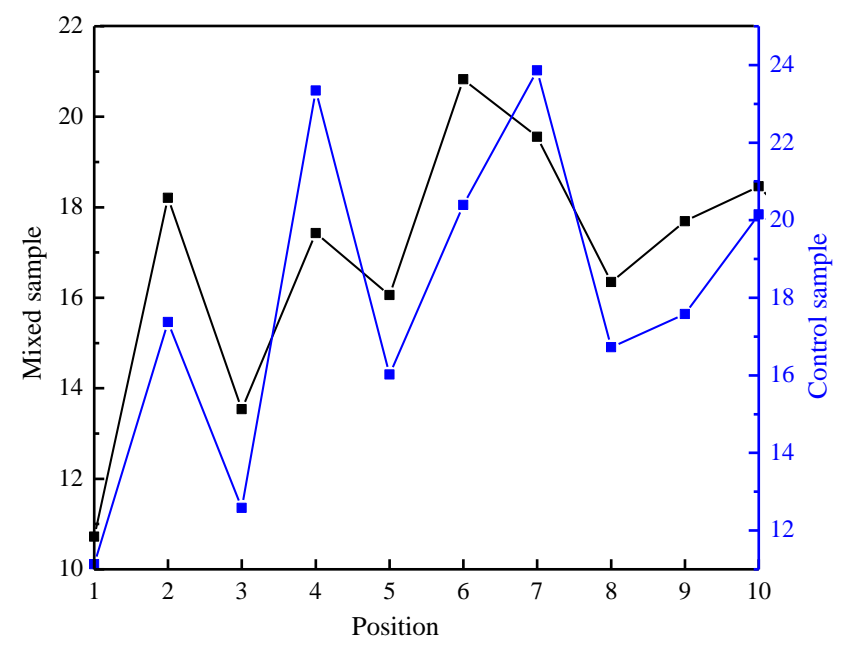

Figure 1. The change of water content of mixed samples and control samples at different sampling points

Figure 2 depicts the porosity changes of mixed samples and control samples at different sampling points. Obviously, the soil is less compacted at a high porosity. The results of porosity analysis show that the soil porosity followed the same trend with development intensity/activity scale. In other words, the environmental impacts of tourism development or tourist activities can be measured by soil porosity. In the ecotourism scenic spot, the heavy metals in soil mainly come from the dusts discharged from nearby factories, the solid wastes carried by tourists and the development of 
tourism facilities. Figure 3 presents the comprehensive pollution index (CPI) of heavy metals at different sampling points. Except a few points, the heavy metal CPI exhibited the same trend with soil porosity, indicating that tourism development and activities will push up the heavy metal CPI in soil.

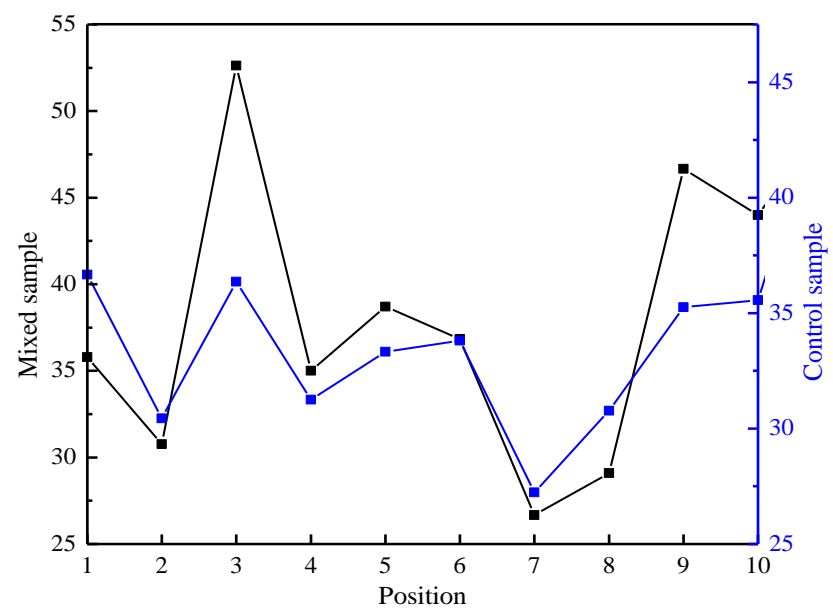

Figure 2. The change of soil porosity of mixed samples and control samples at different sampling points

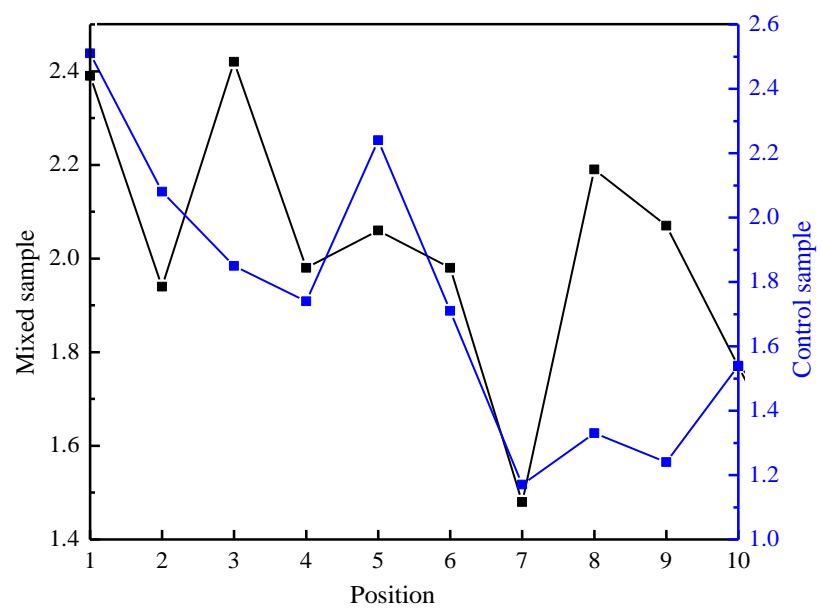

Figure 3. The heavy metal CPIs at different sampling points

\section{Impacts of tourism development and tourist activities on water environment}

By observing the artificial lakes in Xixi Wetland Park, the water environment in the park is found to be dead water, with no river channel to the external water bodies. The water bodies in the park are mainly polluted by tourist toilets, catering, animal foods, surface garbage, etc. On the development intensity/activity scale of tourism, the ten sampling points can be ranked as No. $7>$ No. $8>$ No. $2>$ No. $1>$ No. $4>$ No. $6>$ No. $5>$ No. $10>$ No. $9>$ No. 3 .

The $\mathrm{pH}, \mathrm{COD}$, TAN and turbidity measured at the different sampling points are respectively displayed in Figures 4-7. As shown in these figures, the $\mathrm{pH}$ in lake water remained basically the same across the park. The peak $\mathrm{pH}$ was measured at No. 10 
sampling point, which has the most intense tourist activities. This is attributable to the alkaline wastes left by tourists. The $\mathrm{pH}$ at No. 4 sampling point was not consistent with the development intensity/activity scale, which is probably the result of the acidic substances discharged by surrounding enterprises or residential areas. Thus, the $\mathrm{pH}$ of the water samples can reflect the degree of environmental impacts of tourism development and tourist activities on the ecotourism scenic spot. Besides, the COD and TAN variations could partially demonstrate how tourism development and tourist activities affect the ecotourism scenic spot. However, the two indices may also change due to non-tourism issues like animal wastes. In addition, the turbidity, an indicator of sediments of water bodies, basically agreed with the development intensity/activity scale in change law. To sum up, the impacts of tourism development or tourist activities on scenic ecotourism spots can be demonstrated by the $\mathrm{pH}, \mathrm{COD}$, TAN and turbidity of water bodies.

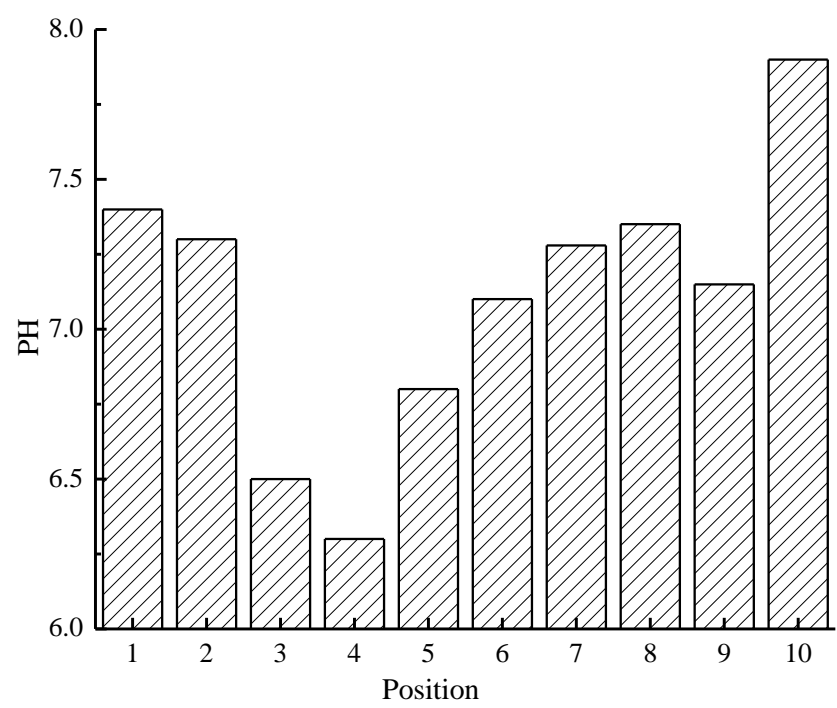

Figure 4. The change of $\mathrm{pH}$ at different sampling points

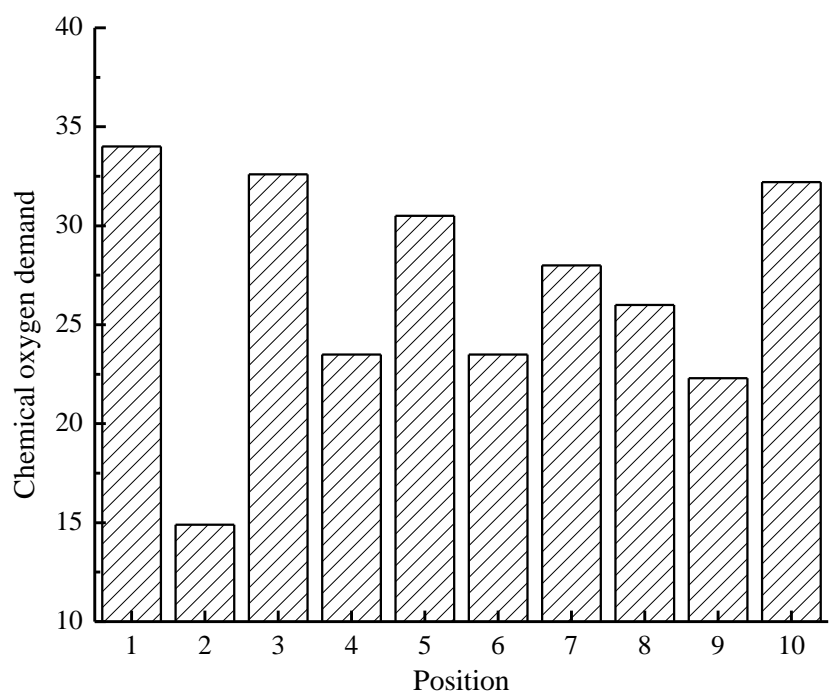

Figure 5. The change of COD at different sampling points 


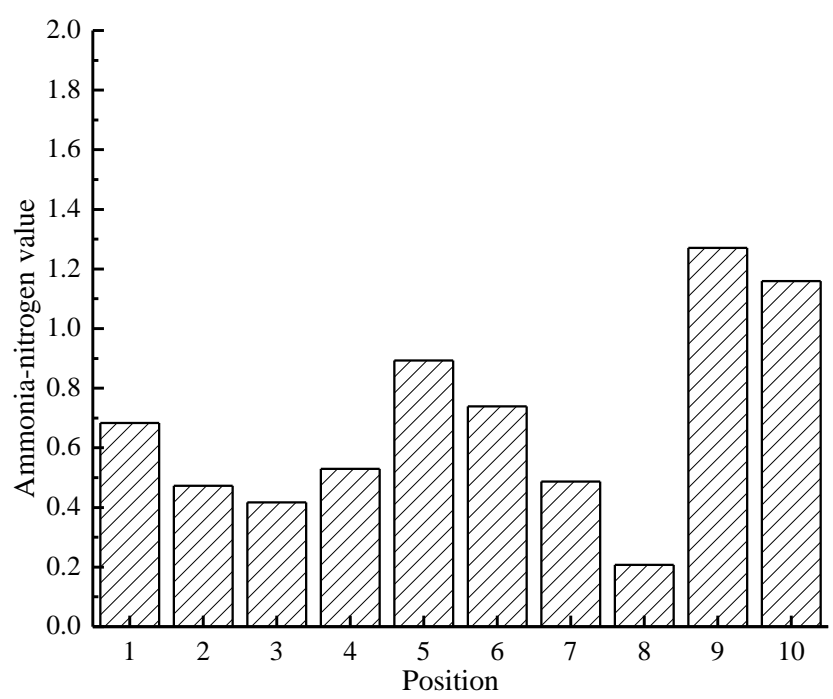

Figure 6. The change of TAN at different sampling points

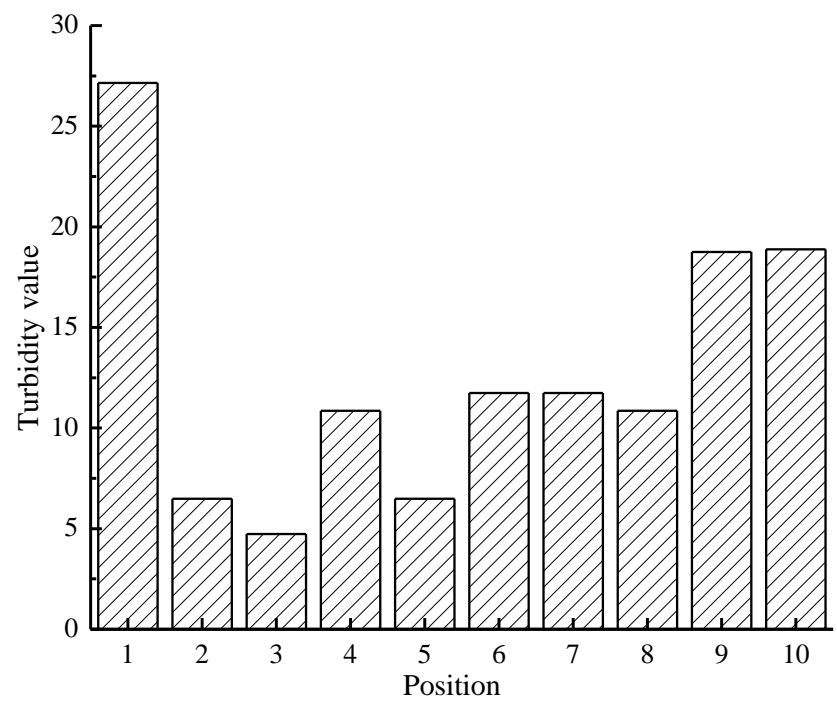

Figure 7. The change of turbidity at different sampling points

\section{Discussion}

\section{Influencing factors of the environment in scenic ecotourism spots}

The change curve of tourist market in Xixi Wetland Park (Figure 8) shows that the number of tourists to the park increases year by year, and peaks from May to August each year. In this section, the author analyzed the tourism development and tourist activities affect the soil and water conditions in the park, and discovered that the environment in the ecotourism scenic spot is influenced in varied degrees by both tourism development and tourist activities. Owing to tourism development and tourist activities, the soil becomes less porous and more compacted. The soil hardness is mostly affected by tourist activities and tourism construction projects. The changing soil environment will suppress the animal diversity in the soil, and directly affect the plant metabolism. 
The water environment has a great regulatory effect on the park. The turbidity increase and $\mathrm{pH}$ change of the water bodies are the combined effect of the garbage left by tourists, the distributions from tour boats and the discharge of various organic matters and minerals. Figure 9 depicts the impacts of travel distance on the relative coverage and the relative number of species. With the growth in travel distance, the relative coverage of species increased annually at a decreasing rate, while the relative number increased first and then decreased.

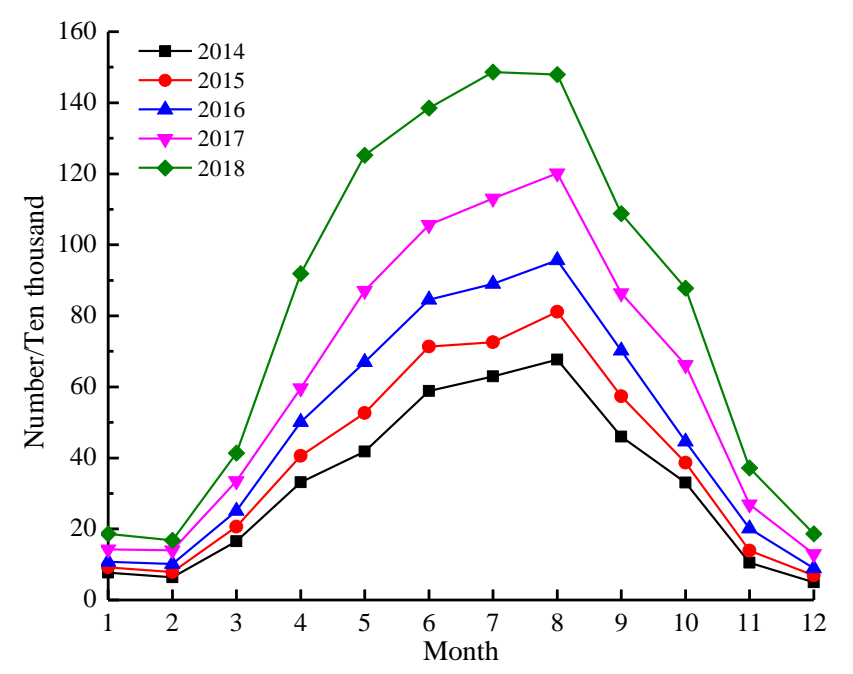

Figure 8. The change of tourist market in Xixi Wetland Park

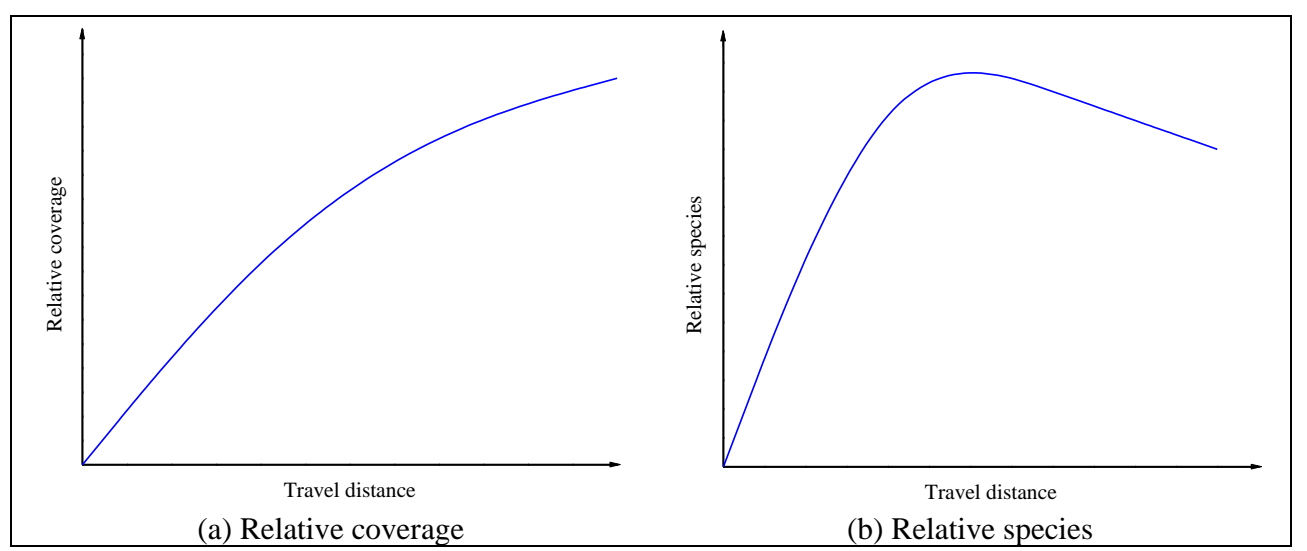

Figure 9. Impacts of travel distance on relative coverage and relative number of species

\section{Measures and suggestions on enhancing environmental protection}

China has not issued any law on ecotourism. In fact, tourism development should be regulated by effective legal means, so should the tourists in tourist activities. Any unit or individual should abide by the planning of scenic ecotourism spots. None should develop tourism projects arbitrarily in violation of regulations. Every ecotourism scenic spot should establish a sound environmental monitoring system. As shown in Figure 10, an effective environmental monitoring system for scenic ecotourism spots should cover four aspects, including ecological environment (air, hydrology, soil and vegetation), 
tourist, rare species and forest resources. The monitor or monitoring department should put forward relevant protection measures after rational evaluation and analysis. Currently, the eco-tourism scenic spots should strengthen the monitoring and control of the tourist activity environment, reasonably control the tourist inflow into the scenic environment, and prevent the eco-tourism scenic spots from overloading and the resulting impacts.

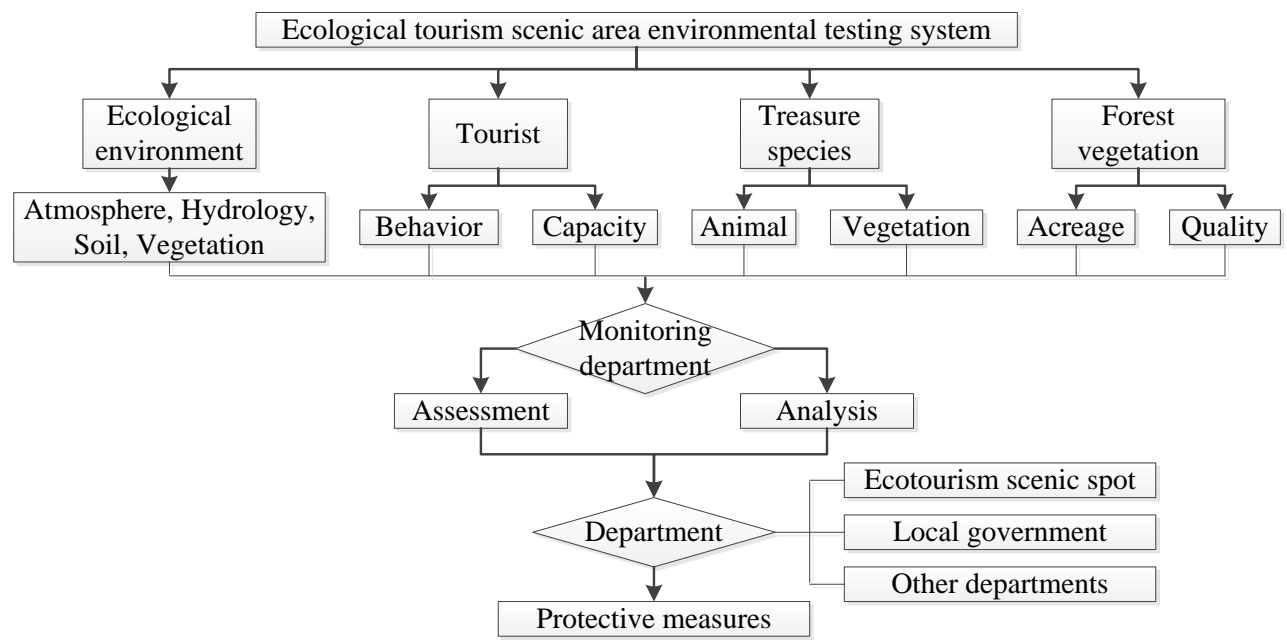

Figure 10. An effective environmental monitoring system for ecological tourism scenic spots

\section{Conclusions}

Taking Xixi Wetland Park for example, this paper explores the effects of tourism development and tourist activities on the soil and water environments in scenic ecotourism spots. The main conclusions are as follows:

(1) The soil is less compacted at a high porosity. Soil porosity is the best indicator of how tourism development and tourist activities affect the environment of scenic ecotourism spots, followed by the heavy metal CPI. By contrast, the water content variation in soil cannot demonstrate the impacts well.

(2) The impacts of tourism development or tourist activities on scenic ecotourism spots can be demonstrated by the $\mathrm{pH}, \mathrm{COD}$, TAN and turbidity of water bodies.

(3) The environment in the ecotourism scenic spot is influenced in varied degrees by both tourism development and tourist activities. With the growth in travel distance, the relative coverage of species increased annually at a decreasing rate, while the relative number increased first and then decreased.

(4) At present, there are few studies on ecological impact evaluation and impact source evaluation of tourism development and activities on eco-tourism scenic spots, and the qualitative and quantitative relationship between them is not clear, with the evaluation indexes involved with each other. The mechanism between ecological impact evaluation indicators and impact sources should be further studied.

Acknowledgements. (1) Henan provincial department of science and technology key research and development and promotion special project (tackling key problems in science and technology): research on the analysis and reconstruction technology of parametric spatial texture characteristics in the development of traditional villages in central China (182102310963), 2018/01-2019/12, presided over 
and under research. (2) Research project of Henan science and technology think tank in 2018: research on regional feature extraction and activation path of traditional villages in central China under the background of rural revitalization (hnkjzk-2019-54b), 2019/01-2019/12, presided over and under research. (3) 2016 Zheng Zhou Institute of Light Industry doctoral research fund funded project: research on the restoration and activation strategy of traditional village texture in the area with remnants and debris-taking Henan province as an example (2016BSJJ061), 2017/01-2019/12, presided over and under research.

\section{REFERENCES}

[1] Anctil, A., Blanc, D. L. (2016): An educational simulation tool for integrated coastal tourism development in developing countries. - Journal of Sustainable Tourism 24(5): 783-798.

[2] Aryal, S., Cockfield, G., Maraseni, T. N. (2018): Globalisation and traditional socialecological systems: understanding impacts of tourism and labour migration to the transhumance systems in the himalayas. - Environmental Development 25: 73-84.

[3] Dillimono, H. D., Dickinson, J. E. (2015): Travel, tourism, climate change, and behavioral change: travelers' perspectives from a developing country, nigeria. - Journal of Sustainable Tourism 23(3): 437-454.

[4] Iliev, D. (2018): Regional inequalities and contemporary problems in regional tourism development: a case of macedonia. - Anatolia 29(3): 368-378.

[5] Ingelmo, I. A. (2013): Design and development of a sustainable tourism indicator based on human activities analysis in inle lake, myanmar. - Procedia-Social and Behavioral Sciences 103: 262-272.

[6] Ke, L. (2012): New development direction on worse ecological system resource of china eco-tourism. - Energy Procedia 14: 445-450.

[7] Lyon, A., Hunter-Jones, P., Warnaby, G. (2017): Are we any closer to sustainable development? listening to active stakeholder discourses of tourism development in the waterberg biosphere reserve, south africa. - Tourism Management 61: 234-247.

[8] Mbaiwa, J. E. (2011): Changes on traditional livelihood activities and lifestyles caused by tourism development in the okavango delta, botswana. - Tourism Management 32(5): 1050-1060.

[9] Movono, A., Dahles, H., Becken, S. (2018): Fijian culture and the environment: a focus on the ecological and social interconnectedness of tourism development. - Journal of Sustainable Tourism 26(3): 451-469.

[10] Olafsdóttir, R., Runnstrom, M. C. (2009): A gis approach to evaluating ecological sensitivity for tourism development in fragile environments. a case study from SE iceland. - Scandinavian Journal of Hospitality and Tourism 9(1): 22-38.

[11] Saarinen, J., Lenao, M. (2014): Integrating tourism to rural development and planning in the developing world. - Development Southern Africa 31(3): 363-372.

[12] Sigurðardóttir, I., Steinthorsson, R. S. (2018): Development of micro-clusters in tourism: a case of equestrian tourism in northwest iceland. - Scandinavian Journal of Hospitality and Tourism 18(3): 261-277.

[13] Wu, C. C., Tsai, H. M. (2016): Capacity building for tourism development in a nested social-ecological system - a case study of the south penghu archipelago marine national park, taiwan. - Ocean \& Coastal Management 123: 66-73. 